\title{
Fetal brain MRI: how it added to ultrasound diagnosis of fetal CNS anomalies-1 year experience
}

\author{
Mariam Raafat ${ }^{1,2^{*}}$ (D), Mahmoud Alalfy ${ }^{3}$, Omar Nagy $^{3}$ and Samira Saraya ${ }^{2}$
}

\begin{abstract}
Background: Central nervous system (CNS) anomalies are the most commonly diagnosed abnormalities of all fetal malformations and are usually primarily discovered on routine prenatal ultrasonography (US). Fetal magnetic resonance imaging (MRI) is a non-invasive technology with high soft tissue contrast that is documented to increase the diagnostic accuracy for detection of fetal brain anomalies.

The aim of our study is to analyze the value of adding magnetic resonance imaging (MRI) of the fetal brain to antenatal ultrasound in the diagnosis of fetal central nervous system (CNS) anomalies.

Results: We diagnosed various CNS anomalies including twelve cases with infra- and supra-tentorial arachnoid cysts, six cases had Dandy-Walker malformation (DWM) and its variants, 1 case with mega cisterna magna, 2 cases of holoprosencephaly, 1 case of hydranencephaly, 2 cases with supratentorial hydrocephalus, 1 case of craniopharyngioma, 6 cases with corpus callosum (CC) agenesis, 1 case of extradural hematoma, and 8 cases with Meckel-Gruber syndrome (MGS). MRI diagnosis confirmed the ultrasound finding, without additional information in 23 cases (57.5\%\%), added an extra finding in 11 cases (27.5\%), differentiated between 2 pathologies in 3 cases (7.5\%), and changed the diagnosis in 3 cases $(7.5 \%)$.

The 40 pregnancies resulted in 27 births (67.5\%), 2 died directly after birth (5\%), 7 terminations (17.5\%), and 4 intrauterine fetal deaths (IUFD) (10\%).

Conclusion: Ultrasound is the gold standard imaging modality for anomaly scan in the second and third trimesters; however, MRI of the fetal brain might be a clinically valuable complement especially when ultrasound examination is inconclusive due to maternal obesity, severe oligohydramnios, or in complicated cases with unclear diagnosis.
\end{abstract}

Keywords: Fetal, MRI, CNS

\section{Background}

Central nervous system (CNS) anomalies are the most commonly diagnosed abnormalities of all fetal malformations and are usually primarily discovered on routine prenatal ultrasonography (US). The incidence of CNS abnormalities is $0.14-0.16 \%$ in live births and reaches $3-$

\footnotetext{
* Correspondence: mariam_raafat@yahoo.com

${ }^{1}$ Radiology Department (Women's Imaging Unit), Kasr Al-Ainy Hospitals, Cairo University, Cairo, Egypt

${ }^{2}$ Diagnostic and Intervention Radiology Department, Faculty of Medicine,

Cairo University Hospitals, Kasr Al-Ainy, Cairo, El-Manial 11956, Egypt

Full list of author information is available at the end of the article
}

$6 \%$ in stillbirths [1]. They are the most common reason for pregnancy terminations owing to their poor longterm outcomes [2].

Prenatal ultrasound is the main stay tool for diagnosing structural abnormalities, with a high diagnostic accuracy for brain abnormalities [3].

Fetal magnetic resonance imaging (MRI) is a noninvasive technology with high soft tissue contrast that is documented to increase the diagnostic accuracy for detection of fetal brain anomalies by about $16 \%$ when compared to ultrasound [4] and helps in refining prognostic information for $20 \%$ of already diagnosed cases [5].

\section{Springer Open}

() The Author(s). 2021 Open Access This article is licensed under a Creative Commons Attribution 4.0 International License, which permits use, sharing, adaptation, distribution and reproduction in any medium or format, as long as you give appropriate credit to the original author(s) and the source, provide a link to the Creative Commons licence, and indicate if changes were made. The images or other third party material in this article are included in the article's Creative Commons licence, unless indicated otherwise in a credit line to the material. If material is not included in the article's Creative Commons licence and your intended use is not permitted by statutory regulation or exceeds the permitted use, you will need to obtain permission directly from the copyright holder. To view a copy of this licence, visit http://creativecommons.org/licenses/by/4.0/. 
Fetal MR imaging is useful when imaging by ultrasound is challenging as in cases of severe oligohydramnios, maternal morbid obesity, difficult fetal head position, and advanced gestational age where shadowing from fetal calvarium interferes with ultrasound images [6].

The aim of our study is to analyze the value of adding magnetic resonance imaging (MRI) of the fetal brain to antenatal ultrasound in the diagnosis of fetal central nervous system (CNS) anomalies.

\section{Methods}

\section{Patients}

A prospective study was done between November 2019 and November 2020 on 40 fetuses who were sonographically suspected or diagnosed to have CNS anomalies. Maternal age ranged from 19 to 35 years and gestational age was between 18 and 36 weeks. Patients were recruited during their routine antenatal care referred from Obstetrics and Gynecology department, at our institute after performing their routine anomaly scan by US. MRI was performed during the same week of US examination. This study was approved by the local Scientific review board Committee. An informed written consent was obtained from each lady.

\section{Ultrasonography}

Ultrasound examination was performed using 2 machines: Voluson 730 ProV (GE Healthcare, Milwaukee, WI, USA) and Voluson 730 D 3D-US system (kretztechnik AG, Zipf, Austria). Ultrasound was made by two well-experienced sonographers in the field of fetal medicine. The following factors were evaluated in every fetus: assessment of gestational age, fetal number, viability, position and biophysical profile, and amniotic fluid index. Detailed anomaly scan included assessment of the fetal brain. Optimal US criteria for assessment of fetal brain were proper fetal head and brain position either in the transverse or sagittal section, low maternal abdominal fat, and average amount of liquor.

\section{MRI}

All patients were imaged by a 1.5 - $\mathrm{T}$ super conducting magnet (Gyroscan Achieva Philips Medical Systems, Best, The Netherlands) using the synergy body coil in supine position. After a scout acquisition, a series of fetal images in the axial, sagittal, and coronal planes were obtained either with balanced fast field echo (B-FFE) using repetition time/echo time (TR/TE) of 3.5/1.7, flip angle (FA) $80^{\circ}$, matrix $256 \times 256$, field of view (FOV) $300-$ 400 , and thickness/gap of $5 / 0 \mathrm{~mm}$ or single shot fast spin echo [SSFSE] sequence with TR/TE of 15000/120, FA $90^{\circ}$, matrix of $169 / 256$, FOV $200-300$, and thickness/ gap of $3-4 / 0-0.5 \mathrm{~mm}$. In addition in some cases, T1weighted sequence was performed in the axial plane only
(TR/TE $120 / 4$, FA $70^{\circ}$, matrix $166 / 256$, FOV 300, thickness/gap of $5 / 0.5 \mathrm{~mm}$ ). The total examination time was between 15 and $25 \mathrm{~min}$.

Images were examined independently by two radiologists with 10 years' experience in the fetal MRI field.

The radiologists were not informed about the ultrasound findings before the MRI examination. Antenatal ultrasound and MRI findings were revised as regards the final diagnosis, which was based on the evaluation of all available data including post-natal radiological follow-up and autopsy results.

\section{Fetal outcome}

In cases where pregnancy continued, and the fetus survived, the antenatal diagnosis was confirmed through post-natal neuroimaging using transcranial ultrasonography, CT, or MRI. In cases of termination of pregnancy, stillbirth, or neonatal death, the final diagnosis of the CNS anomaly was confirmed, based on autopsy.

\section{Statistical analysis}

The clinical data were described in terms of range, mean, (number of cases), and percentages when appropriate. Accuracy was calculated to test validity of MRI compared to ultrasonography. Agreement between the two modalities was calculated using Kappa test.

\section{Results}

Forty single fetuses who were suspected or diagnosed to have CNS abnormalities were incorporated in this research. The maternal age ranged between 19 and 35 years with a mean age of 27 years. The gestational age ranged between 18 and 36weeks (mean age $=27$ weeks). The CNS anomalies diagnosed by MRI included $12 \mathrm{fe}-$ tuses with infra- and supra-tentorial arachnoid cysts, 6 cases with Dandy-Walker malformation and its variants, 1 case with mega cisterna magna (diagnosed as posterior fossa arachnoid cyst before MRI), 2 cases of holoprosencephaly, 1 case of hydranencephaly, 2 cases with

Table 1 Number of cases with their final diagnosis

\begin{tabular}{lll}
\hline CNS anomaly & Number of cases & Percentage \\
\hline Arachnoid cyst & 12 & 30 \\
Dandy-Walker and its variants & 6 & 15 \\
Mega cistern magna & 1 & 2.5 \\
Alobar holoprosencephaly & 2 & 5 \\
Hydranencephaly & 1 & 2.5 \\
Supra-tentorial hydrocephalus & 2 & 5 \\
Craniopharyngioma & 1 & 2.5 \\
CC agenesis & 6 & 15 \\
Extradural hematoma & 1 & 2.5 \\
Meckel-Gruber syndrome & 8 & 20 \\
\hline
\end{tabular}


Table 2 Impact of MRI on diagnosis

\begin{tabular}{lll}
\hline Impact of MRI & Number of cases & Percentage \\
\hline Confirmed the diagnosis with no additional findings & 23 & $57.5 \%$ \\
Confirmed the diagnosis and added an extra finding & 11 & $27.5 \%$ \\
Differentiated between 2 pathologies & 3 & $7.5 \%$ \\
Changed or gave new diagnosis & 3 & $7.5 \%$ \\
\hline
\end{tabular}

supratentorial hydrocephalus, 1 case of craniopharyngioma, 6 cases with corpus callosum agenesis, 1 case of extra-dural hematoma, and 8 cases with Meckel-Gruber syndrome (Table 1).

MRI was made during the same week of ultrasound examination. The performed MRI confirmed the US finding, without additional information in 23 cases (57.5\%), added an extra finding in 11 cases $(27.5 \%)$, differentiated between 2 pathologies in 3 cases (7.5\%), and changed diagnosis in 3 cases (7.5\%) (Table 2).

The overall diagnostic accuracy of US was $98.8 \%$ and of MRI was $99.6 \%$.

In 12 cases with arachnoid cysts, MRI confirmed the diagnosis and clearly depicted them without adding any extra information in 9/12 cases; however in the other 3 cases, MRI added extra-findings which were posterior parietal meningocele in one case (Fig. 1), polymicrogyria in another case, and partial CC agenesis as well as inferior vermian hypoplasia in the third case.

Concerning the 6 cases of Dandy-Walker malformation and its variants, MRI gave no additional findings in 4/6 cases; while in 1/6 case with US diagnosis of Blake's pouch cyst, MRI showed additional mild ventriculomegaly and partial corpus callosum agenesis and added the presence of a small parietal meningocele in one of the cases of DW malformation. Conversely, MRI refuted the diagnosis of a posterior fossa arachnoid cyst (based on ultrasound) and instead a mega cisterna magna was diagnosed.

In 3 cases of marked cerebral hypoplasia being replaced by large CSF area seen by US, MRI differentiated between alobar holoprosencephaly and hydranencephaly, through presence or absence of inter-hemispheric fissure.

In the 2 cases with ultrasound diagnosis of hydrocephalus, MRI confirmed the diagnosis and clearly defined the cause to be aqueductal stenosis.

Regarding the case of suprasellar mass lesion with consequent obstructive hydrocephalus as detected by ultrasound, MRI confirmed the diagnosis with better delineation of its extent; both modalities having suggested craniopharyngioma (Fig. 2) and autopsy confirmed the diagnosis.

In addition, MRI also confirmed 3/6 cases diagnosed as corpus callosum agenesis by second trimester US, adding no extra findings (Fig. 3). However, in the other 3 cases with CC agenesis (3/6), MRI showed additional polymicrogyria in one case, inferior vermian hypoplasia in the second case, and high riding third ventricle communicating with widened inter-hemispheric cistern in the last one.

Extra-dural hematoma was only diagnosed on MRI, where a definitive diagnosis was not possible by prenatal ultrasound.

In cases with Meckel-Gruber syndrome (MGS), MRI added no extra findings in 6/8 diagnosed cases, and only US visualized polydactyly. Additional findings on MRI in the remaining 2 cases included an occipital meningocele in one case (Fig. 4) and a small parietal meningocele in addition to a case diagnosed with bilateral polycystic kidneys; thus, MRI altered the diagnosis from mere renal disease to Meckel-Gruber syndrome.

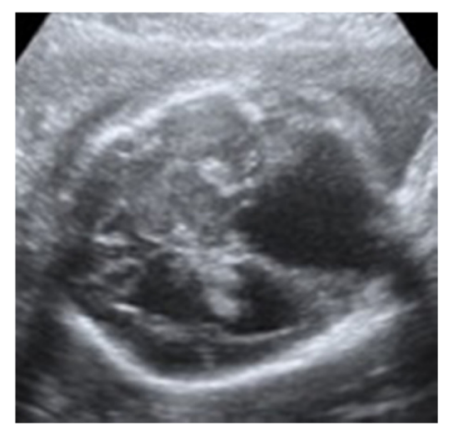

(a)

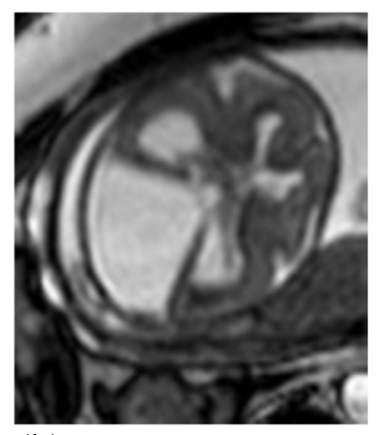

(b)

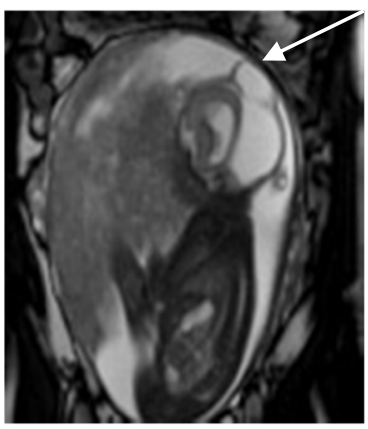

(c)

Fig. 1 Twenty-five-week fetus a US showed infratentorial arachnoid cyst. b, c Axial and sagittal MRI (B-FFE) images confirmed the diagnosis and added the presence of posterior parietal meningocele (arrow) 


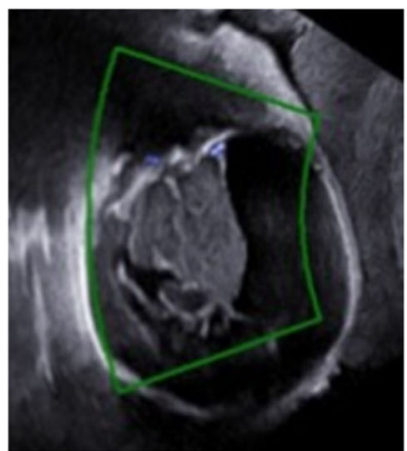

(a)

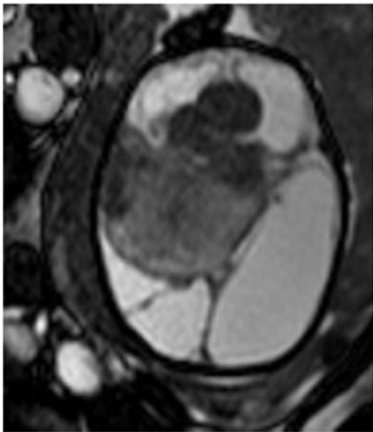

(b)

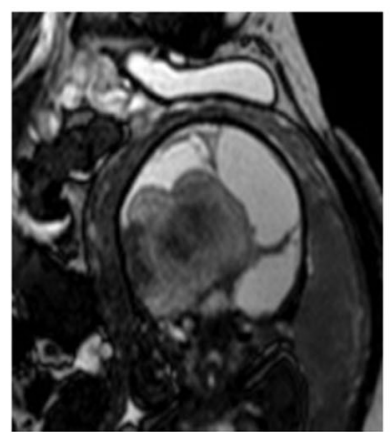

(c)

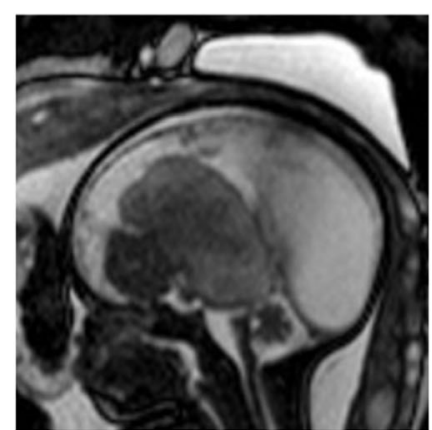

(d)

Fig. 2 Twenty-eight-week fetus a US axial plane shows right para-midline suprasellar mass lesion with consequent supratentorial hydrocephalus. b-d MRI (B-FFE) axial, coronal, and sagittal planes confirmed the presence of large supra-sellar mass with better delineation of its extent, mass effect, and consequent supratentorial hydrocephalus. Autopsy confirmed the diagnosis of craniopharyngioma

The 40 pregnancies resulted in 27 births $(67.5 \%), 2$ died directly after birth (5\%), 7 terminations (17.5\%), and 4 intrauterine fetal deaths (IUFD) (10\%).

Comparison between the different statistical data between the US and MRI is shown in Table 3, and agreement between the two modalities is shown in Table 4 .

\section{Discussion}

Ultrasound is still the first-line modality for fetal scanning being readily available, of low cost, and provides the advantage of assessing blood flow of the fetus and providing a dependable data about fetal development. However, in cases like morbid maternal obesity, oligohydramnios, and ossified skull, in late pregnancy together with cases showing inconclusive results, US needs an adjuvant examination to collect more accurate information in case of indefinitive diagnosis [7].

Magnetic resonance imaging arised as a tool of fetal examination since 1983. Its inherent advantages, being operator independent, having high resolution, superior soft tissue contrast, wide field of view, multiplanar capability, as well as lacking ionizing radiation, have encouraged its use as a problem-solving tool in diagnosing fetal anomalies diagnosed by US [7].

The guidelines made by the American College of Radiology for MR practices in 2013 sanctions recommends doing fetal MRI at any time during gestation if the benefits exceeds the possible risks for the woman and the fetus [8]. However, up to current moment, there is no proof that MRI is unsafe for the fetus, yet not enough studies were made to confirm its safety performance. Recommendations are to do MRI after 18 weeks of gestation due to unknown biological effects of high magnetic fields during organogenesis [9].

Our study is a prospective study dealing with fetal CNS anomalies diagnosed between 18 and 36 weeks gestation. We compared US and MRI results with fetal post natal outcome or autopsy of abortus and cases with

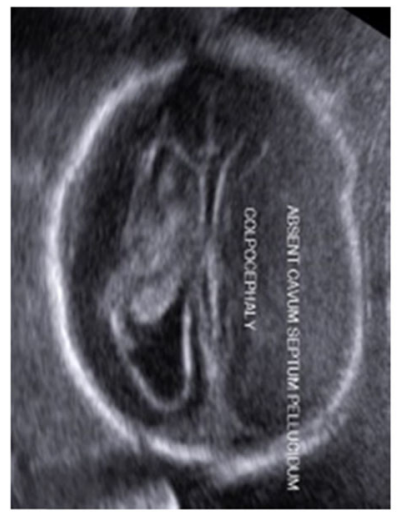

(a)

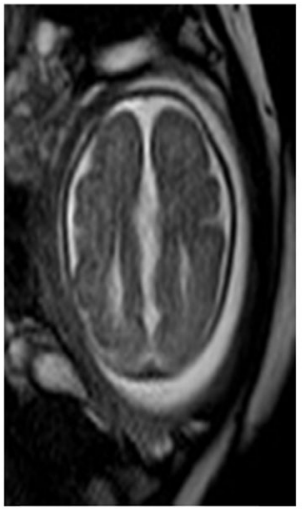

(b)

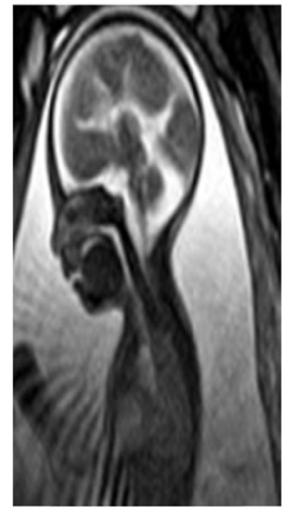

(c)

Fig. 3 Twenty-seven-week fetus a US showed absent septum pellucidum and colpocephaly. b, c Axial and sagittal MRI (B-FFE) images showed parallel orientation of the lateral ventricular bodies and confirmed the diagnosis of CC agenesis 


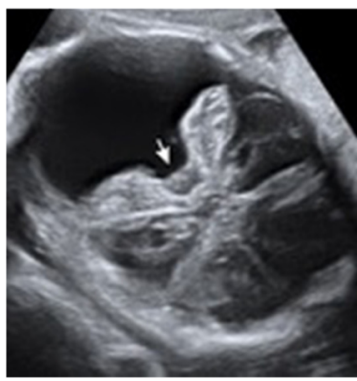

(a)

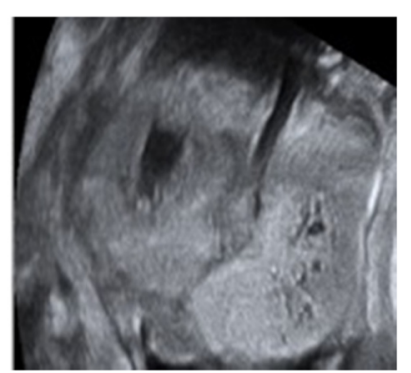

(b)

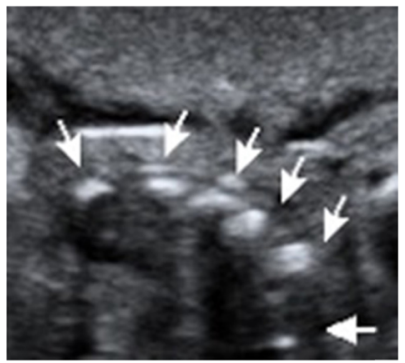

(c)

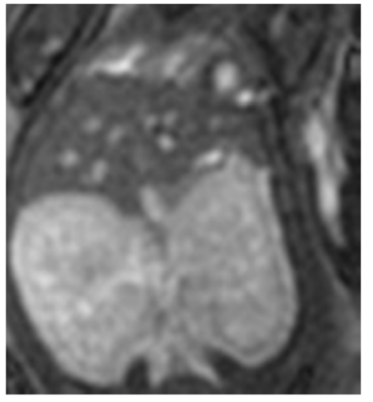

(d)

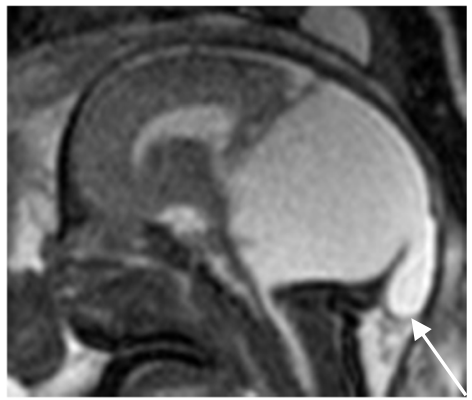

(e)

Fig. 4 Twenty-nine-week fetus a US trans-cerebellar plane shows fourth ventricle communicating with enlarged cystic retro-cerebellar space filled with CSF (arrow). b US of the abdomen shows enlarged echogenic kidneys. c US showing polydactyly (arrows). d MRI (B-FFE) of the abdomen confirming bilateral polycystic kidneys. e MRI (B-FFE) of the brain confirming Dandy-Walker malformation added the presence of small occipital meningocele(arrow). Post natal MRI confirmed the diagnosis of Meckel-Gruber syndrome

IUFD, where the patients were consented for the autopsy.

We compared the diagnostic accuracy of prenatal MRI to that of ultrasound in the diagnosis of CNS anomalies between 18 and 36 weeks gestation, and this diagnosis was confirmed by the fetal post natal outcome; postnatal transcranial US, CT, or MRT and autopsy in cases of termination or IUFD if the patient consented for autopsy.

Obtained MRI confirmed US diagnosis, without additional information in $23 / 40$ cases (57.5\%), added an extra finding in 11/40cases (27.5\%), differentiated between 2 pathologies in $3 / 40$ cases $(7.5 \%)$ and changed diagnosis in $3 / 40$ cases $(7.5 \%)$.

These results are comparable to the results of Frates et al. [10], who performed fetal MRI for 28 cases; in which 14 (50\%) of 28 cases, the diagnoses made by US and MR imaging were accurate when compared with post-natal diagnosis. MRI supplied more information than did US in 7 of the 14 (25\% of total) fetuses but added no data in 7 others. There were no fetuses in which US added additional information to that provided with MRI when both were correct. In 7 (25\%) of 28 cases, diagnoses with both US and MRI were incorrect when matched with postnatal diagnosis.

Amini et al. [11] made a study about fetal CNS abnormalities in the second trimester and found that fetal MRI in second trimester delivered additional diagnostic data compared to the ultrasound scan in $45 \%$ of the cases, which resulted in a change in the management in $10 \%$ of all cases.

In the present study, MRI had a sensitivity of $97.5 \%$ compared to $95 \%$ for US; this is in agreement with a study made by Gonçalves et al. [12] who found that MRI was more sensitive than 2DUS and 3DUS.

Several studies revealed a higher accuracy of MRI in comparison to US for the diagnosis of CNS anomalies [13-16]; this agrees with our study that revealed an overall accuracy for MRI 99.6\%, with PPV $=95.4 \%$ and $\mathrm{NPV}=99.9 \%$ compared to $98.8 \%$ for US with PPV= 90.5\% and NPV=99.9\%. However, Malinger et al. [17]

Table 3 Comparison of the diagnostic performance as well as agreement between MRI and US

\begin{tabular}{lllllllll}
\hline & Sen & Spec & PPV & NPV & Accuracy & K & SE of K & 95\% Cl for K \\
\hline US & $95.0 \%$ & $98.5 \%$ & $90.5 \%$ & $99.9 \%$ & $98.8 \%$ & 0.939 & 0.042 & $0.857-1.000$ \\
MRI & $97.5 \%$ & $99.6 \%$ & $95.4 \%$ & $99.9 \%$ & $99.6 \%$ & 0.970 & 0.030 & $0.912-1.000$ \\
\hline
\end{tabular}

Sen sensitivity, Spec specificity, PPV +VE predictive value, NPV -VE predictive value, $K$ Kappa value, SE standard error, $C I$ confidence interval 
Table 4 Agreement between both US and MRI

\begin{tabular}{|c|c|c|c|c|}
\hline & Kappa & SE of Kappa & 95\% Cl for Kappa & Strength of agreement \\
\hline Arachnoid cyst & 0.942 & 0.057 & $0.830-1.000$ & Very good \\
\hline Meckel-Gruber syndrome & 1.000 & 0.000 & $1.000-1.000$ & Perfect \\
\hline CC agenesis & 1.000 & 0.000 & $1.000-1.000$ & Perfect \\
\hline Dandy-Walker malformation & 1.000 & 0.000 & $1.000-1.000$ & Perfect \\
\hline Supratentorial hydrocephalus & 1.000 & 0.000 & $1.000-1.000$ & Perfect \\
\hline Blakes pouch cyst & 1.000 & 0.000 & $1.000-1.000$ & Perfect \\
\hline Alobar holoprosencephaly & 1.000 & 0.000 & $1.000-1.000$ & Perfect \\
\hline Hydranencephaly & 1.000 & 0.000 & $1.000-1.000$ & Perfect \\
\hline Joubert syndrome & 1.000 & 0.000 & $1.000-1.000$ & Perfect \\
\hline Craniopharyngioma & 1.000 & 0.000 & $1.000-1.000$ & Perfect \\
\hline Mega cisterna magna & 0.000 & 0.000 & $0-0$ & Poor \\
\hline Extradural hematoma & --- & ---- & --- & ---- \\
\hline
\end{tabular}

disagrees with these results they revealed a higher accuracy for fetal neurosonography in $7 / 39$ (17.9\%) cases in comparison to the accuracy for MRI in 3/39 (7.7\%) cases.

Paladini et al. [18] examined 126 fetuses by 2D-US, 3D-US, and MRI where he concluded that MRI and ultrasound results were disagreeing in $12.7 \%(16 / 126)$, with additional diagnostic information provided by MRI in $7.9 \%(10 / 126)$ of cases.

In our study MRI added an extra-finding in $11 / 40$ cases(27.5\%), differentiated between 2 pathologies in 3 /40cases (7.5\%), and changed diagnosis in $3 / 40$ cases ( 7.5 $\%)$.

\section{Strengths and limitations of the study}

The strengths of this study are (1) the blinded and randomized image revision by experienced examiners, (2) specific comparison of diagnostic confidence rates between examiners, and (3) interpretation bias was reduced by preventing access to patient history or findings from prior diagnostic imaging studies.

Limitation of this study was the number of fetuses studied due to limited awareness of fetal MR imaging, as well as financial issues.

\section{Conclusion}

Ultrasound is the gold standard imaging modality for anomaly scan in the second trimester; however, MRI of the fetal brain might be a clinically valuable complement especially when ultrasound scan is inconclusive due to maternal obesity, severe oligohydramnios or in complicated cases with unclear diagnosis.

\section{Abbreviations}

CNS: Central nervous system; US: Ultrasound; MRI: Magnetic resonance imaging; DWM: Dandy-Walker malformation; CC: Corpus callosum; MGS: Meckel-Gruber syndrome; B-FFE: Balanced fast field echo; TR: Time of repetition; TE: Time of echo; FOV: Field of view; FA: Flip angle

\section{Acknowledgements}

No acknowledgments

Authors' contributions

MR: contributed in the study conception and design, collecting patients' data, writing and editing the manuscript. MA: helped in collecting and interpretation of data. ON: referral and follow-up of the cases. SS: helped in the study deign and statistical analysis. All authors read and approved the final manuscript.

Funding

No funding sources

Availability of data and materials

Available with the corresponding author upon request

\section{Declarations}

Ethics approval and consent to participate

Written informed consent was signed by all patients before examination. The study was approved by the ethics committee of faculty of medicine Cairo University. Reference number is not applicable.

\section{Consent for publication}

All patients included in this research are above 16 years and all gave written informed consent to publish the data contained within this study.

\section{Competing interests}

The author declare that to have no competing interests

\section{Author details}

${ }^{1}$ Radiology Department (Women's Imaging Unit), Kasr Al-Ainy Hospitals, Cairo University, Cairo, Egypt. ²Diagnostic and Intervention Radiology Department, Faculty of Medicine, Cairo University Hospitals, Kasr Al-Ainy, Cairo, El-Manial 11956, Egypt. ${ }^{3}$ Reproductive Health and Family Planning Department,

National Research Centre, Dokki, Giza, Egypt.

Received: 20 January 2021 Accepted: 14 March 2021

Published online: 25 March 2021

\section{References}

1. Onkar D., Onkar P., and Mitra K., "Evaluation of fetal central nervous system anomalies by ultrasound and its anatomical correlation," J Clin Diagn Res,(2014) vol. 8, no. 6, pp. AC05-AC07, 2014.

2. Goergen SK, Alibrahim E, Govender N., . Stanislavsky A. and Abel C. "Diagnostic assessment of foetal brain malformations with intra-uterine MRI versus perinatal post- mortem MRI" Neuroradiology (2019) 61:921-934.

3. Eros FR, Simonyi A, Tidrenczel Z, Szabo I, Rigo J Jr, Beke A (2018) Efficacy of prenatal ultrasound in craniospinal malformations according to 
fetopathological and postnatal neonatological, pathological results. Fetal Pediatr Pathol 37(3):166-176

4. Jarvis D, Mooney C, Cohen J, Papaioannou D, Bradburn M, Sutton A Griffiths PD (2017) A systematic review and meta-analysis to determine the contribution of MR imaging to the diagnosis of foetal brain abnormalities in utero. Eur Radiol 27(6):2367-2380

5. Griffiths PD, Bradburn M, Campbell MJ, Cooper CL, Graham R, Jarvis D, Kilby MD, Mason G, Mooney C, Robson SC, Wailoo A (2017) Use of MRI in the diagnosis of fetal brain abnormalities in utero (MERIDIAN): a multicentre, prospective cohort study. Lancet 389:538-546

6. Glenn OA, Barkovich J (2006) Magnetic resonance imaging of the fetal brain and spine: an increasingly important tool in prenatal diagnosis: Part 2 AJNR. Am J Neuroradiol 27:1807-1814

7. Sefidbakht S, Dehghani S, Safari M, Vafaie H, Kasraeian M (2016) Fetal central nervous system anomalies detected by magnetic resonance imaging: a two-year experience. Pediatrics 26(4):e4589

8. Ghavami M, Abedinzadeh R (2011) Prevalence of perinatal central nervous system anomalies in East azarbaijan-iran. Iran J Radiol. 8(2):79-81

9. Valevic viene NR, Varyte G, Zakarevic viene J, Kontrimavic lu Te E, Ramašauskaite D, DR V (2019) Use of magnetic resonance imaging in evaluating fetal brain and abdomen malformations during pregnancy. Medicina:55

10. Frates MC, Kumar AJ, Benson CB, Ward VL, Clare M, Tempany MD (2004) Fetal anomalies: comparison of MR imaging and US for diagnosis radiology. 232:398-404

11. Amini H, Axelsson O, Raiend M, Wikstom J (2010) The clinical impact of fetal magnetic resonance imaging on management of CNS anomalies in the second trimester of pregnancy. Acta Obstet Gynecol 89:1571-1581

12. Gonçalves LF, Lee W, Mody S, Shetty A, Sangi-Haghpeykar H, Romero R (2016) Diagnostic accuracy of ultrasonography and magnetic resonance imaging for the detection of fetal anomalies: a blinded case-control study. Ultrasound Obstet Gynecol 48(2):185-192

13. Garcia-Flores J, Recio M, Uriel M, Canamares M, Cruceyra M, Tamarit I, Carrascoso J, Espada M, Sainz de la Cuesta R (2013) Fetal magnetic resonance imaging and neurosonography in congenital neurological anomalies: supplementary diagnostic and postnatal prognostic value. J Matern Fetal Neonatal Med 26:1517-1523

14. Griffiths PD, Porteous M, Mason G, Russell S, Morris J, Fanou EM, Reeves MJ (2012) The use of in utero MRI to supplement ultrasound in the foetus at high risk of developmental brain or spine abnormality. Br J Radiol. 85: e1038-e1045

15. Whitby EH, Paley MN, Sprigg A, Rutter S, Davies NP, Wilkinson ID, Griffiths PD (2004) Comparison of ultrasound and magnetic resonance imaging in 100 singleton pregnancies with suspected brain abnormalities. BJOG. 111: 784-792

16. Blaicher W, Prayer D, Mittermayer C, Weninger M, Birnbacher R, Deutinger J, Bernaschek $G$ (2005) The clinical impact of magnetic resonance imaging in fetuses with central nervous system anomalies on ultrasound scan. Ultraschall Med. 26:29-35

17. Malinger G, Ben-Sira L, Lev D, Ben-Aroya Z, Kidron D, Lerman-Sagie T (2004) Fetalbrain imaging: a comparison between magnetic resonance imaging and dedicatedneurosonography. Ultrasound Obstet Gynecol. 23:333-340

18. Paladini D, Quarantelli M, Sglavo G, Pastore G et al (2014) Accuracy of neurosonography and MRI in clinical management of fetuses referred with central nervous system abnormalities. 44:188-196

\section{Publisher's Note}

Springer Nature remains neutral with regard to jurisdictional claims in published maps and institutional affiliations.

\section{Submit your manuscript to a SpringerOpen ${ }^{\circ}$ journal and benefit from:}

- Convenient online submission

- Rigorous peer review

- Open access: articles freely available online

High visibility within the field

- Retaining the copyright to your article

Submit your next manuscript at $\boldsymbol{\nabla}$ springeropen.com 